\title{
Kültür ve Reklam İlişkisi
}

\author{
Hatice Nur YILDIZ ${ }^{1}$ \\ $\ddot{O}_{z}$
}

Reklamlar hem kültürü etkilemekte hem de kültürden etkilenmektedir. Reklamlar toplumu tüketime yönlendirme, kadın veya erkeğe belirli roller çizme, insanları tek tipe dönüştürme ve insanların alışkanlıklarını değiştirme gibi görevler üstlenerek toplumu etkileme gücüne sahip olmaktadır. Ayrıca toplumun kültürel özelliklerini, toplum için önemli olay ve ögeleri anlatarak toplumun kültürünü de yansitabilmektedir. Toplumun aynası olmak isteyen reklamların başarılı olabilmesi için o toplumun kültürünü doğru şekilde yansıtmaları gerekmektedir. Makalede kültüre vurgu yapan Boyner grubu tarafindan yapılan "Bizim Tarzımız Güzel” ve "Hediye Demek, Boyner Demek" isimli reklamlar, içerik ve söylem analizi yapılarak incelenmiş ve Hofstede'nin kültür boyutları bağlamında değerlendirilmiştir. Kültürün reklamlarda nasıl işlendiğini ortaya koymak amacıyla yapılan bu çalışmada, reklamlarda kullanılan dilin çözümlenmesinde söylem analizinden, görüntülerin çözümlenmesinde ise içerik analizinden faydalanılmıştır. Araştırmada, Boyner reklamlarında hangi kültürel ögelere yer verildiği, bu ögelerin ve karakterlerin nasıl konumlandırıldığı ve Hofstede'nin kültürel boyutlarından hangilerinin bahsedildiği incelenmiştir. İncelenen reklamlarda Hofstede'nin kültür boyutlarından kollektivizm ve uzun dönem oryantasyonu ön plana çıarken, düşük belirsizlikten kaçınma ve dişilik boyutlarının da yer aldığı görülmektedir.

Anabtar Kelimeler: Reklam, Kültür, Hofstede, Kültürel Boyut, Reklam ve Kültür ilişkisi

\section{Relations between Culture and Advertising}

\begin{abstract}
Ads affect culture and are affected by culture. Advertisements have the power to influence the society by taking on tasks such as swaying the society to consumption, providing specific roles to men or women, standardizing people changing people's habits. It can reflect the society's culture by explaining the cultural characteristics of the society, important events and elements for the society. Ads wanting to be the society's mirror must reflect the culture of that society correctly to be successful. In this article, the ads named "Bizim Tarzımız Güzel" and "Hediye Demek, Boyner Demek", emphasize on culture and are prepared by the Boyner group were analyzed by analyzing content and discourse and evaluated in the context of Hofstede's cultural dimensions. Discourse analysis was used to analyze the language used in advertisements, and content analysis was used to analyze images in this article aiming to reveal how culture is handled in advertisement. In the research, which cultural elements are included, how these elements and characters are positioned, which cultural dimensions of Hofstede are mentioned were examined. While collectivism and long-term orientation which are in Hofstede's cultural dimensions become prominent, low uncertainty avoidance and femininity dimensions are mentioned.
\end{abstract}

Key Words: Advetising, Culture, Hofstede, Cultural Dimension, Relations Between Advertising and Culture

\section{Atıf İçin / Please Cite As:}

Yıldız, H. N. (2022). Kültür ve reklam ilişkisi. Manas Sosyal Araştırmalar Dergisi, 11(1), 293-308.

Geliş Tarihi / Received Date: 25.02.2021

Kabul Tarihi / Accepted Date: 13.08.2021

\footnotetext{
${ }^{1}$ Arş. Gör. - Atatürk Üniversitesi İletişim Fakültesi, haticenur.yildiz@atauni.edu.tr

iD ORCID: 0000-0001-8282-4676
} 


\section{Giriş}

Ekonominin ön plana çıtı̆ğı 21. yüzyılda işletmeler, yaşanan yoğun rekabet ortamı içerisinde var olabilmek için rakiplerinden daha çok bilinirlilik yoluna gitmektedir. Bu bağlamda ise reklamlar ön plana çıkmaktadır. Reklam, bir işletmenin veya markanın ismi belli olacak şekilde, ürün veya hizmetlerini hedef kitlelere duyurmak için yaptıkları tanıtım veya tutundurma çabalarının tümü olarak ifade edilebilmektedir. Kitle iletişim araçları üzerinden yapılan reklamlar aracılığı ile markalar ürünlerini veya hizmetlerini genişs kitlelere etkili bir şekilde duyurma imkânı yakalamaktadır. Fakat reklamların başarılı olabilmesi için, reklam kampanya sürecinde hedef kitlenin özelliklerinin doğru bir şekilde belirlenmesi gerekmektedir.

Özellikle geniş kitlelere ulaşmak isteyen markalar için sınırların kalkması ile birlikte hedef kitlenin sahip olduğu kültür; reklam ve tanıtım faaliyetlerinin odak noktası haline gelmektedir (Yılmaz ve Mazlum, 2009, s. 59). Kültür, toplumdan topluma farkllilk gösteren ve her toplumun kendi içerisinde yaşayan grupların paylaşttğı ortak değerler, inanışlar, gelenekler gibi sembollerin ve unsurların bütünü olarak ifade edilmektedir. Toplumdan topluma farklılık göstermesinden dolayı uluslararası pazarlara giriş yapmak isteyen işletmeler, o toplumlarla ilgili kültürü de iyi bilmelidir. Örneğin, bir markanın reklamlarında oynaması için seçilen oyuncunun o toplum tarafindan sevilip sayılması, geleneksel kadın figürüne uyan oyuncuların seçilmesi veya toplum için önemli olan bayram veya günlerde özel reklamlar yayınlanması kültür ve reklam ilişkisini başarılı bir şekilde yansıtmaktadır. Fakat reklam ve kültür ilişkisi sadece tek taraflı bir çerçevede gelişmemektedir. Reklamlar kültürleri yansıttığı gibi kültürleri de etkilemektedir. Özellikle reklamların insanların düşüncelerinde ve yaşam şekillerinde de etkili olduğu düşünülmektedir. Reklamın üstlendiği her iki rolde de toplumların kültürel boyutlarının belirlenmesi önem kazanmaktadır.

Reklam ve kültür ilişkisinin içerik ve söylem analizi yapilarak Hofstede'nin kültürel boyutları bağlamında incelendiği çalısmada; reklam ve kültür kavramı açıklanarak, reklam ve kültür arasındaki ilişkiye değinilmiştir. Çalışma kapsamında; "Bizim Tarzımız Güzel” ve "Hediye Demek Boyner Demek" sloganı ile toplumun kültürüne ve yaşam tarzına dikkat çeken Boyner grup tarafindan hazırlanan reklam ele alınmıştır. İncelenen reklamlarda kültürel ögeler tespit edilmiş ve reklam içeriklerin Hofstede'nin belirlediği kültürel boyutlar bağlamında ele alınmıştır.

\section{Reklam Kavramı ve Kültür Kavramı}

Türk Dil Kurumu (TDK) tarafindan "Bir şeyi halka tanıtmak, beğendirmek ve böylelikle sürümünü sağlamak için denenen her türlü yol" şeklinde tanımlanan reklam (Türk Dil Kurumu Sözlükleri, 2020), Amerikan Pazarlama Birliği’ne (American Marketing Association) göre bir ürün, hizmet, organizasyon veya fikirler hakkında hedef kitlelerini bilgilendirmek veya ikna etmek isteyen işletmeler, kar amacı gütmeyen kuruluşlar, devlet kurumları veya bireyler tarafindan, belirlenen zamanda duyuruların ve mesajların yerleştirilmesi olarak ifade edilmektedir(American Marketing Association [AMA], 2020). Marka farkındalığının oluşmasını sağlayan pazarlama iletişim karmalarından biri olan reklam (Uribe, 2016, s. 460), markaya karşı ilgisiz olan tüketicilerde ilgi uyandırılmasını sağlayan çabalardır (Hartnett, Romaniuk ve Kennedy, 2016, s. 21). Elden, Ulukök ve Yeygel'e (2005, s. 62) göre ise, reklam, bir ürün ya da hizmetin, bedeli kimin tarafından ödendiği belli olacak şekilde, geniş kitlelere tanıtılması için kitle iletişim araçlarından yer ve zaman satın alınarak yapılan çabaların bütününü içermektedir. Yapılan tanımlar göz önünde bulundurulduğunda reklamın belirli bir ücret karşılığında yapıldığı, reklamı yapan kişinin belli olduğu, ürün veya hizmetlerin tanıtımının yapılmasında kitle iletişim araçlarının kullanıldığı sonucuna varılabilmektedir. Fakat reklamın özellikleri detaylı olarak şu şekildedir (Topsümer ve Elden, 2016, s. 16):

- Reklam, pazarlama iletişimi içerisinde yer almaktadır.

- Reklam, reklam verenden tüketiciye doğru giden iletiler bütünüdür.

- Reklam mesajları, kitle iletişim araçları ile hedef kitleye iletilmektedir.

- Reklamı yapan kişi, kurum ve kuruluş bellidir.

- Reklam aracilığıyla hedef kitle bilgilendirilir ve ikna edilmeye çalışlır.

- Reklam mesajlarında mallar, hizmetler, vaatler, ödüller, sorunlara çözümler bulunmaktadır.

- Reklam, işletmenin belirlediği pazarlama stratejileri doğrultusunda saptanan pazarlama hedeflerine ulaşmak için diğer pazarlama iletişimi elemanları ile koordineli olarak çalışmaktadır.

Globalleşen dünyada uluslararası pazarlara giriş yapmanın işletmeler açısından önemli olduğu açıktır. Uluslararası pazarlara giriş stratejilerinden biri ise toplumların kültürel özelliklerini bilmek ve kültürel farkl1lıkları doğru tespit edebilmektir (Görgün, 2020, s. 18) 
Kültür, bireylerin bilgi birikimlerini, öğrenimlerini, inançlarını, yasalarını, ahlaki kurallarını, geleneklerini, göreneklerini, törelerini ve değerlerini içeren unsurlar bütünüdür (Odabaşı ve Barış, 2017, s. 314). Mucuk'a göre ise, bireylerin isteklerinin en temel nedeni ve belirleyicisi olan kültür, insanların değerleri, örf, adet, ahlak, tutum, inanç, davranış, sanat ve toplumda paylaşılan sembollerin karışımıdır (2014, s. 76). Parker, kültürü, okyanustaki bir buzdağına benzetmektedir. Buzdağının görünen ve görünmeyen olmak üzere iki kısmı olduğu gibi kültürün de iki boyutu bulunmaktadır. Buzdağının görünen kısmı olarak nitelendirilen kültür boyutu içerisinde normlar, adetler, dil ve semboller bulunmaktadır. Buzdağının görünmeyen kısmı olarak ifade edilen kültürün köklerini ise inançlar, değerler ve varsayımlar oluşturmaktadır. Kültürün görünmeyen kısmı, bireylerin, davranışlarını şekillendirmektedir (Parker, 1998 Akt: Yeşil, 2012, s. 43). Kültürü bir sosyal gruptaki insanların paylaştıkları ortak anlamlar olarak ifade eden Koç (2019, s. 399-402) bu ortak anlamları şu şekilde açıklamaktadır:

Ortak Duygusal Reaksiyonlar: Hindistan gibi bazı ülkelerde sevimli görülen fare, Türkiye'de iğrenme veya tiksinme gibi olumsuz duyguları uyandırabilmektedir. Bu nedenden dolayı fare kullanılan bir reklam Türkiye'de başarılı olmayabilir.

Tipik/Karakteristik Bilgiler/İnançlar: İnsanlar tarafindan paylaşılan ortak bilgiler ve inançlar kimi zaman doğru kimi zaman da yanlış olabilmektedir.

Karakteristik Davranış Kalıpları: Asya ülkelerinde görülen görücü usulü evlilikler ile Japonya’daki çay ritüelleri karakteristik davranış kalıplarına örnek gösterilebilmektedir.

Kültür hakkında yapılan tanımlar sşığında kültürü, toplum tarafindan paylaşılan toplumdan topluma farklılık gösteren değerler, gelenekler, inançlar ve ahlaki kurallar gibi sembollerin veya unsurların bütünü şeklinde de ifade etmek mümkündür. Fareler Hindistan'da Tanr1 olarak kabul edilirken, Türkiye'de olumsuz duyguları uyandırmaktadır bu durum ise kültürün toplumdan topluma değişebileceğini göstermektedir. Aynı şekilde Avrupa ülkelerinde tercih edilen domuz ürünlerinin İslâmî ülkelerde yasak olması ise toplum tarafindan paylaşılan değerlere veya inanışlara örnek verilebilmektedir. Bu bağlamda kültürün toplumdan topluma değişmesi kültürün belirli ögeleri içerdiğini göstermektedir. Kültürün ögeleri ve tüketim davranışlarına etkisi Tablo 1. 'de gösterilmektedir.

Tablo 1. Kültürün Ögeleri

\begin{tabular}{ll}
\hline \multicolumn{1}{c}{ Kültürün Ögeleri } & \multicolumn{1}{c}{ Tüketim Davranışlarına Etkisi } \\
\hline Değerler & $\begin{array}{l}\text { Materyalistik değere sahip olup sembolik ürünler alabilir. Çevreyi koruma değeri ile geri dönüşümlü } \\
\text { paketlerde satılan ürünleri tercih edebilir. }\end{array}$ \\
Dil & Marka adlarının, sloganların etkisi \\
İnanışlar ve Mitler & Türbelere adak adamak, iki bayram arası evlenmek \\
Gelenekler & Büyüklerin onayını almak, bayramlarda çocuklara kıyafet almak \\
Törenler & Evlenme, nikah gibi törenler, doğumda şerbet dağtıllması \\
Yasalar & Hollanda'da uyuşturucu kullanımının serbest olması \\
&
\end{tabular}

Kaynak: (Odabaşı ve Barış, 2017, s. 316-317)

Hofstede, semboller, kahramanlar, ritüeller ve değerler olmak üzere 4 kategori saptamıs ve bu kategoriler doğrultusunda da kültürü 5 farklı boyutta incelemiştir (Okumuş, 2018, s. 277-279):

Güç Aralığı: Toplumdaki hiyerarşinin kabulünü ele alan güç aralığı boyutu, dar ve geniş güç aralığı olmak üzere iki ayrılmaktadır. Dar güç aralı̆̆ında insanlar arasındaki ilişkiler demokratik olurken, geniş güç aralığında ise zayıf olanlar, otoriteyi kabullenmekte ve sorgulamamaktadırlar.

Bireycilik ve Toplulukçuluk: Bireyci toplumlarda kişiler kendi istek ve hedeflerini öncelikli tutarken, toplulukçu ülkelerde topluluğun çıkarları bireyin kendi çıkarlarından daha öncelikli olmalıdır.

Erkeksilik ve Kadınsılık: Rekabet, hırs ve maddiyat gibi özellikler erkeksi toplumlarda mevcutken, yaşam kalitesi, eşitlik ve değerler gibi kavramlar kadınsı topluluklarda ön plana çıkmaktadır.

Belirsizlikten Kaçınma: Belirsizlikten kaçınmanın yüksek olduğu toplumlarda bireyler net ve açık kurallar istemektedirler. Yeniye karşı olan tavırları genelde olumsuzdur. Belirsizlikten kaçınmanın zayıf 
olduğu kültürlerde ise kuralların esnek olması bireyleri rahatsız etmez. Bu kültürlerde yeni ürün ve markaların denenme ihtimali yüksektir.

Uzun ve Kısa Döneme Yönelme: Uzun döneme yönelen kültürlerde bireyler geleceğe yönelik hareket ve davranışlara değer vermektedirler. Kısa döneme yönelen toplumlarda ise geleneksel değerlere bağll1ık, kuralcı yaklaşımlar ve değişime direnç gibi kavramlar görülmektedir.

Steers, Sanchez-Runde Nardon'un Hofstede'nin kültürel boyutuna yönelik bilgileri ise Tablo 2'de gösterilmektedir.

Tablo 2. Hofstede'nin Kültürel Boyutlarn

\begin{tabular}{|c|c|c|}
\hline Kültürel Boyutlar & & Ölçek Boyutlatı \\
\hline $\begin{array}{l}\text { Güç mesafesi: Gücün } \\
\text { toplum içerisinde } \\
\text { dağılımının uygunluğuna } \\
\text { yönelik inanç }\end{array}$ & $\begin{array}{l}\text { Düşük Güç Mesafesi: Ast ve üst } \\
\text { ilişkilerinde, üst yönetimde olan kişilerin } \\
\text { astlarla kıaslandığın fazla güce sahip } \\
\text { olmamaları gerektiğine yönelik inanç } \\
\text { Örnek: İsrail, Danimarka, Norveç }\end{array}$ & $\begin{array}{l}\text { Yüksek Güç Mesafesi: Ast ve üst ilişkilerinde, üst } \\
\text { pozisyonda olan kişilerin fazla güce sahip olmaları } \\
\text { gerektiğine yönelik inanış } \\
\text { Örnek: Suudi Arabistan, Malezya }\end{array}$ \\
\hline $\begin{array}{l}\text { Belirsizlikten Kaçınma: } \\
\text { Belirsizlik seviyesinin hoş } \\
\text { görülebilirliği ve bunların } \\
\text { norm oluşturması }\end{array}$ & $\begin{array}{l}\text { Düşük Belirsizlikten Kaçınma: Belirsizliğe } \\
\text { karşı hoşgörünün olması ve belirsizliği } \\
\text { sınırlamak kurallara az ihtiyaç duyulması } \\
\text { Örnek: Danimarka, İngiltere, İsveç }\end{array}$ & $\begin{array}{l}\text { Yüksek Belirsizlikten Kaçınma: } \\
\text { Belirsizliğe karşı hoşgörünün olmaması, belirsizliği } \\
\text { sınırlamak kurallara fazla ihtiyaç duyulması Örnek: } \\
\text { Yunanistan, Japonya, Fransa }\end{array}$ \\
\hline $\begin{array}{l}\text { Bireycilik-kollektivizm: } \\
\text { Bireysel ve grup } \\
\text { çıarlarının önemi }\end{array}$ & $\begin{array}{l}\text { Bireycilik: Bireysel çıkarlar grup } \\
\text { çıarlarından daha öncelikli olması } \\
\text { Örnek: Amerika, Hollanda, İskandinav } \\
\text { Ülkeleri, İngiltere }\end{array}$ & $\begin{array}{l}\text { Kollektivizm: Grup çıkarları genellikle bireysel çıarlardan } \\
\text { göre öncelikli olması } \\
\text { Örnek: Japonya, Kore, Endonezya }\end{array}$ \\
\hline $\begin{array}{l}\text { Erilik-Dişilik: Mal varlı̆̆ı, } \\
\text { yaşam kalitesi gibi } \\
\text { konularda atılganlık ve } \\
\text { edilginliğin karşı karşıya } \\
\text { gelmesi }\end{array}$ & $\begin{array}{l}\text { Erillik: Mal varlı̆̆ı, para ve kişisel } \\
\text { amaçların değer görmesi } \\
\text { Örnek: Japonya, Avusturya, İtalya }\end{array}$ & $\begin{array}{l}\text { Dişillik: güçlü sosyal bağların, yaşam kalitesinin ve } \\
\text { diğerlerinin zenginliğinin değer görmesi } \\
\text { Örnek: İsveç, Norveç, Hollanda }\end{array}$ \\
\hline $\begin{array}{l}\text { Uzun dönem-Kısa } \\
\text { dönem: } \\
\text { İş, yaşam ve ilişkilere } \\
\text { bakış açısı }\end{array}$ & $\begin{array}{l}\text { Uzun Dönem Yönelimi: Gelecek } \\
\text { yönelimidir. Kendini adama, çalışskanlık } \\
\text { ve tasarruf değer görür. Örnek: Çin, } \\
\text { Kore, Japonya }\end{array}$ & $\begin{array}{l}\text { Kısa Dönem Yönelimi: Geçmiş ve şimdiki zaman } \\
\text { yönelimi. Gelenekler ve toplumsal zorunluluklar değer } \\
\text { görür. Örnek: Pakistan, Nijerya, Filipinler, Rusya. }\end{array}$ \\
\hline
\end{tabular}

Kaynak: (Steers, Sanchez-Runde Nardon, 2010 Akt: Sayllk, 2019, s. 1866).

\section{Reklam ve Kültür İlişkisi}

Ghandeharion ve Badrlou, reklamı tüketicilerin kültürlerine açlan bir pencere olarak ifade etmektedir (2018, s. 335). Reklam, ekonomi amacının yanında kültürü şekillendiren değerler, tutumlar ve fikirlerle de ilgilenmektedir ve reklamın içeriği kültürden ayrilamamaktadır (Abdelaal ve Sase, 2014, s. 254). Reklamlar toplumun yaşamından etkilenirken aynı zamanda da gündelik yaşamı da etkilemektedir ve bu ise bireylerin davranışlarını ve değer yargılarını değiştirebilmektedir (Arslan, 2014, s. 60). Kültür ise reklamın algilanmasında rol oynamaktadır (Srivastava, 2010, s. 103).

Reklamın amacı, tüketicilerin satın alacağı ürün ve kültürleri arasında duygusal bağ kurarak pazarlama stratejisi oluşturmaktır (Sucu, 2020, s. 397). Kotler'e göre ise reklamın amac1, bir ürün hakkındaki gerçekleri anlatmak değil, bir çözüm veya hayal satmaktır (2018, s. 141). Günümüzde insanların yaşamını şekillendiren ve kültürel bir faktör haline gelen reklamlarla toplumlar sadece ne alabileceklerini, ne giyebileceklerini değil aslında ne düşüneceklerini, nasıl davranacaklanını ve ne hissedeceklerini de öğrenmektedirler. Başka bir ifade ile reklamlar insanlara duruş, eğilim ve tutum da satmaktadırlar (Çetin, 2014, s. 565). Tüm ifadeler göz önünde bulundurulduğunda reklamların hem toplumu etkiledikleri hem de toplumdan etkilendikleri anlaşılmaktadır.

Toplumdan etkilenme rolünü üstlendiğinde reklamlar; popüler kültürü, marka değerini, aidiyet duygusunu ve toplumsal değerleri yansıtmaktadır. Reklamlar, popüler kültür ürünlerini markalarla buluşturarak onların yeniden üretilmesini sağlarken, bir markanın tüketiciler arasındaki değerini de açıklayabilmektedir. Aynı şekilde azınlık gruplar için hazırlanan reklamlar, kültürel farklılıkları yansıtmasından dolayı tüketicilerde aidiyet duygusunu geliştirirken, toplumsal değerler üzerinde durmasından dolayı tüketiciler tarafindan daha kolay benimsenebilmektedir. Toplumu biçimlendiren öge olarak reklam ise, tüketicileri gerçekten gereksinim duymadıkları ürünleri satın almalarına yönelterek 
materyalizmi desteklemekte ve insanları tek tipe dönüşmelerini sağlayabilmektedir (Peltekoğlu, 2010, s. 123-124).

Reklam ve kültürün aslında iç içe olduğu anlaşılmaktadır. Reklamlar aracıllı̆̆ ile toplumun fikirleri ve düşünceleri değişebilmektedir. Bu durum ise reklamın kültür üzerinde büyük bir etkisi olduğunu göstermektedir. Özellikle her an ve her yerde karşılaşılması reklamların insanların alg1larına rahatlıkla etki etmesini kolaylaştırabilmektedir. Örneğin, reklamlarda kullanılan bir söylemin günlük konuşma dilinde rastlanılması veya kadın ve erkek rollerinin reklamlardaki içerikler aracılığıyla belirlenmesi reklamların kültürü etkilediğini açıklayabilmektedir.

Tüketici davranışlarını anlamanın yollarından biri ise toplumun kültürünü anlamaktır (Peltekoğlu, 2010, s. 132). Bu nedenden dolayı, reklamın başarılı olabilmesi için, işletmenin belirlediği hedef kitlenin özelliklerinin iyi belirlenmesi gerektiği bilinen bir gerçektir. Hedef kitlenin yaşam biçimi, gelenekleri, tutumları, inançları veya düşünceleri doğru bir şekilde belirlenememesi yanlış bir reklam stratejisinin uygulanmasına yol açabilmektedir. Yanlış uygulanan bir reklam stratejisi ise başarı sağlayamayacağı gibi firmanın veya markanın hedef kitle tarafindan da olumsuz algılanmasına neden olabilmektedir. Örneğin, Anadolu'da siyah rengin yas anlamina geldiğini veya Slav ülkelerinde yasın rengi beyaz (Özcan, 2018, s. 275) olduğunu bilmeyen bir marka, canlı ve neşeli bir mesaj ileten reklam stratejisinde siyah renk kullanması belki de doğru mesajları iletemeyecektir. Bu bağlamda reklam stratejileri oluştururken bilinmesi gereken en önemli konulardan biri de hedef kitlenin kültürünün iyi bilinmesidir. Reklam ve kültür ilişkisini sadece reklamların içerisinde bulunması gereken nesne, renk veya şekillerle ifade etmek yeterli olmamaktadir.

Mooji’ye göre, toplumun sahip olduğu kültür, reklamların anlatım biçimine de etki etmektedir ve bu nedenden dolayı da her ülkenin reklam anlatım tekniği birbirinden farklı özellikler göstermektedir. Örneğin, İngiliz kültüründe gruptan ziyade bireysellik ön planda olmasından dolay1, reklamlarında genellikle yalnız bireyler yer almaktadır ve gençler en az yetişkinler kadar bilgili ve otoriter olarak gösterilmektedir. Mesajın dikkat çekmesi önemli bir unsur olmamakta ve mesaj daha az bir şekilde doğrudan iletilmektedir. Reklamlarında bir ürünün nasıl kullanılacağından ziyade nasıl yarar sağlayacağ1 anlatılan İngiliz reklamlarının bir diğer özelliği ise, Avrupa'da yapılan reklam içerisinde sınıf farklılığını gösteren tek reklam çeşididir. Alman reklamlarında, belirsizlikten kaçınmak için standart bir yap1 ve açık bir dil kullanılmaktadır. İngiliz reklamlarının aksine, Alman reklamlarında belirsizlikten kaçınmak için mizaha pek yer verilmemektedir. Genelde ünlülerin tavsiyelerine, önerilerine veya test sonuçlarına yer verilen Alman reklamlarının, İngiliz reklamlarından ayrılan bir diğer özelliği ise, ürünlerin teknik ve bilimsel ayrıntılarını açıklamak, sağlayacağı faydayı belirtmekten daha önemlidir. Kollektivzm ve konfüçyonist geleneğini benimseyen Japon reklamlarında ise, doğrudan anlatılan bir reklam, tüketici için onur kırıcı olarak düşünülmektedir. Japon reklamlarının amac1, tüketicilerle uzun süreli ilişkiler oluşturmak ve onların saygılarını kazanmaktır. Tüketicinin memnuniyeti, markanın kimliğinden, şirketin isminden daha önemli olmaktadır (Mooji 1998 akt: Aktuğlu ve Çolakoğlu, 2011, s. 18-20).

\section{Yöntem}

Çalışmada, reklam filmlerinde kültürel ögelerin nasıl konumlandırıldığ1 ve kültürün ögeleri içerik analizi yapılarak incelenecektir. İçerik analizi; bireysel, grup, kurumsal veya sosyal ilginin odağının keşfedilmesine ve tanımlanmasına izin veren yararlı bir teknik olabilmektedir (Stemler, 2000, s. 1). İçerik analizi metinden geçerli analizler yapmak için kullanılan bir yöntemdir ve metinsel materyali sınıflandırarak daha alakalı, yönetilebilir veri parçalarına indirgemektedir. İçerik analizi; bireyin, grubun ve toplumun odağını ortaya çıkarmakta, kişi ve grupların psikolojik durumunu belirlemektedir (Weber, 1990, s. 5,9).

Dilin sembolik olmas1, bireyin dünya görüşünü yansıtmas1, toplumun bir sorununu ya da olay1 şekillendirme biçimi olması ve toplumun beklenti ve tutumlarını şekillendirmesi (Balc1, 2016, s. 195) açısından dilin reklamda kullanılma şekli önemli olmaktadır. Bu bağlamda kültür vurgusu olarak dilin kullanımı söylem analizi ile incelenecektir. Söylem analizi, bir söylemin yapısını ve biçimini göstermeyi amaçlayan metinsel-dokümanter bir analizdir. Söylem analizi; anlamlar, güç ve bilgi üzerine yoğunlaşmakta ve sosyal ve kültürel yapıların nasıl şekillendiği ile ilgilidir (Balc1, 2016). Çalışmanın incelemiş olduğu konu çerçevesinde aşağıdaki sorular belirlenmiştir:

1. Reklamda, toplumun sahip olduğu hangi kültürel ögelere yer verilmiştir?

2. Reklamda kültürel ögeler nasıl konumlandırılmıştır? 
3. Kültür vurgusu olarak hangi söylemler hangi metinsel, görsel ve işitsel unsurlarla ön plana çıkarılmıştır?

4. Reklamda karakterler, kültürün anlatılması için nasıl kullanılmıştır?

5. Hofstede'nin kültürel boyutlarından hangilerine değinilmiştir?

6. Reklam ve kültür ilişkisi açısından reklamlar hangi rolü üstlenmiştir?

\section{Evren - Örneklem}

Bu çalışmada, reklamlarda gösterilen kültürel ögeler Hofstede'nin kültür boyutları kapsamında analiz edilerek reklam ve kültür ilişkisi belirlenmeye çalışlacaktır. Bu kapsamda incelenen reklamlar, kültürel ögeleri içinde barındıran ve kültüre vurgu yapan sloganlar içeren televizyon reklamlarından seçilmiştir. Reklamların belirlenmesinde Türkiye'de satışı yapılan reklamlar olmasına dikkat edilmiştir. Örneklem seçiminde, ölçütün amaca uygunluğu açısından "amaçlı örnekleme" yöntemi kullanılmıştır. Örneklem seçiminde amaçlı örneklem yönteminin kullanıldığı çalışmada, güncel olması için 2020 yılında yayınlanmış ve kültürel mesajların öne çıtı̆̆ı reklamlar ele alınmıştır. Bu bağlamda "Bizim Tarzımız Güzel" ve "Hediye Demek, Boyner Demek" sloganına sahip olan Boyner reklamları içerik ve söylem analizleri ile incelenmiştir.

\section{Bulgular}

\section{Boyner “Bizim Tarzımız Güzel” Reklam Filmi}

Reklam filmi hızlı, kısa ve parçalı görüntülü geçişlerle başlamaktadır. Bu ise postmodernizmin ${ }^{2}$ temelinde yaşanılan hızlı yaşam, gösterilen kesik ve parça parça görüntülerde bir anlam bütünlüğünün olmaması insanlar açısından bazı şeylerin anlamlarını yitirmesine işaret ettiği düşünülmektedir.

Reklam filmi, ipe asılan giysilerin rüzgârla sallanması ile net bir şekilde başlamaktadır. Reklamın, açılış görüntüsü olan asıll çamaşırlar, genellikle eski Türkiye sokak kültüründe karşılaşılabilecek sahnelerden biri olmasına rağmen hala toplumsal olarak bir kültürü veya bir yaşam biçimini simgelemektedir. Çamaşırların asılı olduğu sahnenin çerçevesi incelendiğinde, sağda tarihi yapı olan Galata kulesi görünürken, sol tarafta ise gökdelenler ve plazalar yer almaktadır. Modern ve geleneği birleştiren öge ise, bankın yanında yer alan "Boyner" markalı çantadır.

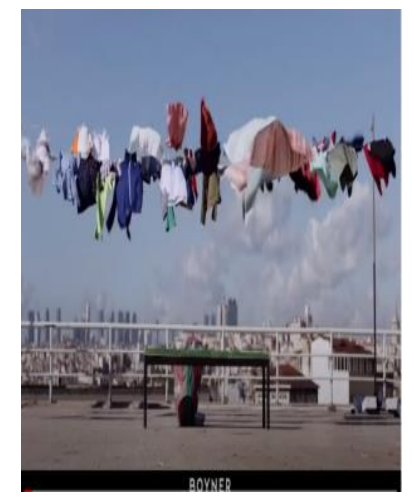

Resim 1. Boyner "Bižim Taržmız Güzel”" Reklam Filmi Açıllş Görseli

. Modern ve geleneğin birleştiği sahneden sonra, geçişlerde Türk kültürü içerisinde yer alan hamam geleneğinin bir ögesi olan peştamalı, punk tarzı giyinen bir gencin döndürmesi, eski ve asırlık bir halı üzerinde günümüz gençliği olarak gösterilen makyajlı bir genç kızın uzanması ve topuklu ayakkabının görünmesi gençler ile geleneğin birleştirildiği mesajını vermektedir. Ulusal sınırlar ise kırmızı ve beyaz renkler göstererek çizilmektedir.

ReklamPunk tarzı giyinen gençlerin kısa görüntüleri ile hızlı bir geçiş yaparak devam etmektedir

"Kimse inkâr edemez biżim milletçe bir taržmız var" söylemi ile devam eden reklam, bu söylem ile aslında Türk toplumunun sahip olduğu ortak kültüre, değerlere ve yaşam biçimlerine vurgu yapmaktadır. Söylemin ardından beyaz dantel çerçeve içerisinde daha önce görünen beyaz koltuk üzerinde yarı uzanarak oturan,

\footnotetext{
2 Modernizm'in aksine postmodernizmde bütünlügün aksine parçalar ve belirsizlik savunularak montaj ve kolaj teknikleri kullanılmaktadır. Postmodernistler için, gerçek ve düş ayırt edilemez (Karadeniz, 2020, s. 52).
} 
siyah kısa şortu, fileli çorabı ile Punk tarzını simgeleyen genç bir kızın kendinden yaşça büyük kadınlara kolonya dökmesi ile devam etmektedir.

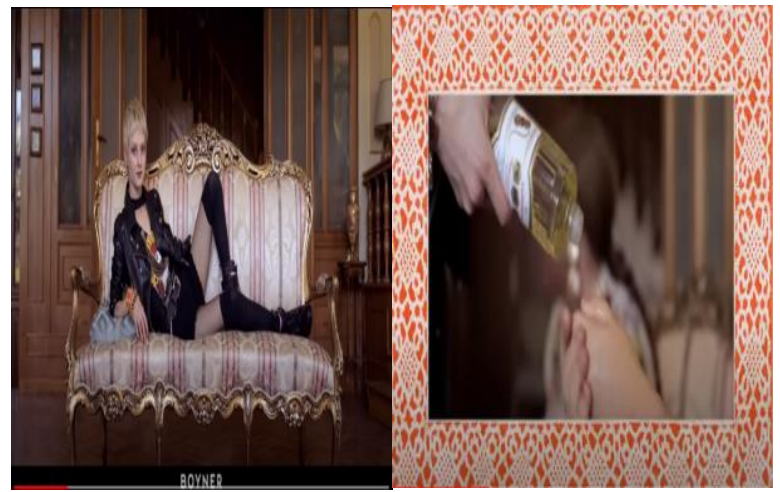

Resim 2. Boyner "Biæim Tarzımı Gǚel” Reklam Filmi Misafir Görseli

Kültürel açıdan bakıldığında, gençler, toplumun normlarını reddeden bir kıyafet tercih etmelerine rağmen toplumdan kendilerini soyutlamamış ve geleneklerinin gerektirdiklerini de yapmışlardır. Asi bir tarz giyimine sahip olan kızın, gelenekleri reddeden yaşam biçimi sunması beklenirken, kızın evlerine gelen misafirlere kolonya dökmesi ve bundan da memnunluk duyması genç kızı yabancılaşma durumundan uzaklaştırmaktadır. Hem kızın hem de yaşça büyük olan kadınların yüz ifadeleri birbirlerini benimsediklerini ve yaşam şekillerine saygılı olduklarını göstermektedir. Toplumun onayını almayı başarabilen genç takdir görmektedir. Bu durum hem düşük belirsizlikten kaçınma hem de uzun dönem ilişki boyutlarını açıklamaktadır. Düşük belirsizlikten kaçınmada, farklı olan tehlikeli sayılmamakta ve farklılı̆̆a karşı saldırgan bir tavır sergilenmemektedir. Gençlerin yaşadıkları koşullara rağmen geleneklerini sürdürmeleri uzun dönem oryantasyon boyutuna işaret etmektedir.

Toplumsal olarak biçilen rol açısından bakıldığında; misafirlere kızın kolonya dökmesi toplumsal rolü destekleyen bir mesaj olarak verilmektedir. Fakat bu sahnede kız, alçaltıcı bir kimliğe büründürülmemektedir. Başka bir ifade ile kadın ve erkek eşitsizliğine vurgu yapılmamaktadır. Kültürel ögeler açısından incelendiğinde ise dantellerin ön plana çıktığı görülmektedir. Beyaz danteller, Türk toplumunda kadınların hayaller kurarak veya bir araya gelerek sohbet ettikleri uğraşlarından biri olarak görülmektedir. Güzel hayaller ve iyi niyetlerle genç kızların çeyizlerine yerleştirilen danteller, bazen de genç kızların duygularının yansıması olarak görülmüştür.

"Sadece parklarda sabillerde koșmayı biそ, yardma kosmayı da biliriz" söylemi ile başlayan sahne, ilk söylemi ile Türk toplumunda yardımlaşmanın önemli olduğunu vurgulamaktadır. Yardımlaşmanın aslında Türk kültüründe var olduğu mesajını iletmektedir.

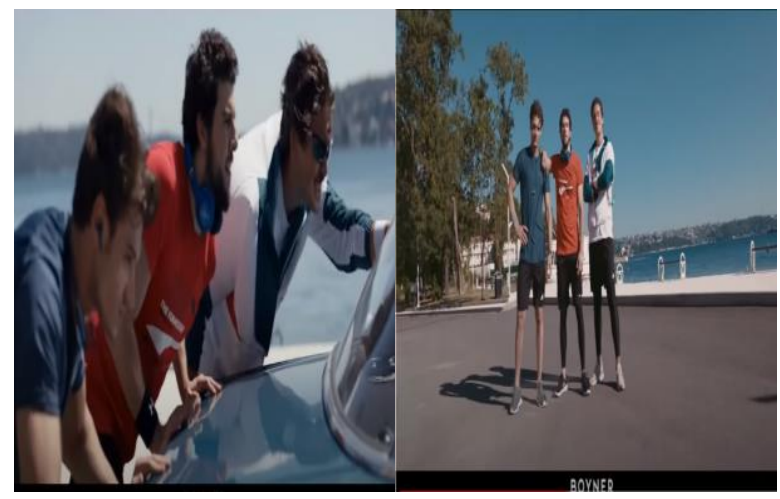

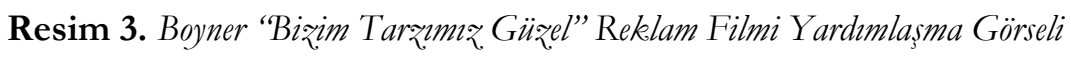

Kültürel açıdan bakıldığında; güçlü durumdaki bireylerin güçsüzlere yardım ettiği görülmektedir. Bu bağlamda muhtaca yardım etme özelliğini içeren dişil boyut görülmektedir. Aynı zamanda insanlar arası ilişkilerin ön plana çıarılmasından dolayı dişil kültüre vurgu yapan bu sahnede; toplulukçuluk izleri bulunmaktadır. Özellikle söylemde "biz" ifadesinin kullanılması ve yardımlaşmanın yapılması toplulukçuluğu gösteren işaretlerdendir. 
"Cesuruz ama nazardan da korkarı, değmesin diye neler yapmayı". söylemi ile başlayan sahnede Türk kültüründe önemli yeri olan nazar inancı vurgulanmaktadır. Geleneksel ve modern dünyayı birleştiren reklam filminin bu sahnesinde, erkeklere ait bir dünyanın kalmadığı ve bir kadının da ayakkabısını boyatabileceği ve boyayan erkeğin de bu durumu garipsemediği görülmektedir. Geleneksel ve modernin birleşimi, bu sahnede de kadının aksesuarlarının altın ve eski tarz olmasına rağmen teknolojiyi de kullanması ile gösterilmektedir.

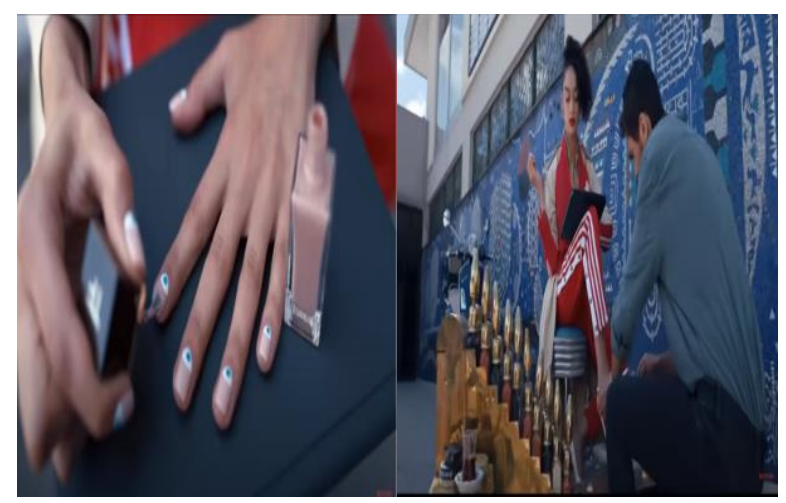

Resim 4. Boyner "Bižm Tarұ̨mı Güzel” Reklam Filmi Nazar Boncuğu Görseli

Resim 4'de gösterilen sahne incelendiğinde bir kafa karışıklığının olduğu da düşünülmektedir. Eşofman ve stiletto stili bir ayakkabının aslında farklı yaşam tarzlarını ifade etmesine rağmen birlikte kombinlenmesi gençlerdeki kafa karışıklığını gösterebilmektedir. Geleneksel olan nazar boncuğu figürünün ise oje olarak kullanılması yine kültürel ögelerden vazgeçilemeyeceğine işaret etmektedir.

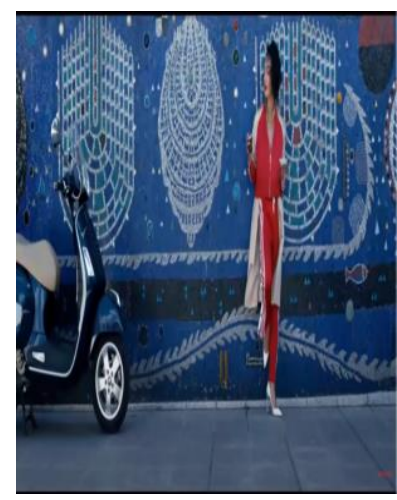

Resim 5. Boyner "Biz̧im Taræ̨ımı Güzel”’ Reklam Filmi Eşofmanlı Kız Görseli

Reklam içerisinde yer alan ve resim 5'de gösterilen görüntüde ise, kırmızı ve beyaz renklerde eşofman giyen genç bir kadının, duvara yaslanarak çay içtiği ve sağ tarafinda duran lüks bir motosiklete baktığ1 görülmektedir. Sahne incelendiğinde, duvarların üzerinde kültürel motifleri anımsatan resimlerin olması ve kadının duvara yaslanması, kadının aslında kültürüne yani geçmişe sırtını dayaması olarak yorumlanmaktadır. Fakat kadının motosiklete bakması ise, geçmişe sırtını dayarken yüzünü geleceğe döndüğünü anlatmaktadır.

Kültürel açıdan bakıldığında; Genelde erkeklerde görülen dışarıda ayakkabı boyatmak veya resim 5'de gösterilen duvara yaslanarak bir ayağını kaldırarak çay içme pozisyonu reklamda kadın tarafından yapılmaktadır. Bu bağlamda değerlendirildiğinde reklamda kadın ve erkek rollerinin örtüştüğü ve kesin bir çizgiyle ayrılmadığı toplumları ifade eden Hoftsede'nin dişilik boyutu görülmektedir. Kültürel ögeler açısından incelendiğinde ise, nazara karşı korunması için kullanılan ve geleneksel olan nazar boncuğu göze çarpmaktadır. Ayrıca, Türk kültüründe önemli bir yer tutan çay ve yaygın olduğu düşünülen çay tabağ1 deseni de belirgin kültürel ögelerdendir.

"Baz̨en dısardan bakan der ki bu da bir değişik, hâlbuki gözde farklı özde aynıyız" söylemi ile başlayan sahne ise belki de eski ve yeni tarzın bir arada yaşamasını fakat yeninin pek kabul görmediğini anlatan ifadelerden birisidir. Tarzları açısından toplum tarafindan farklı görülen insanların da geçmişlerini unutmadıklarını ve geleneklerini sürdürdüklerini ifade etmektedir. Bu sahnede de spot 1ş1kları ile hamamın 1ş1klarının birleşimi geçmiş ve geleceğin birleşimini göstermektedir. 


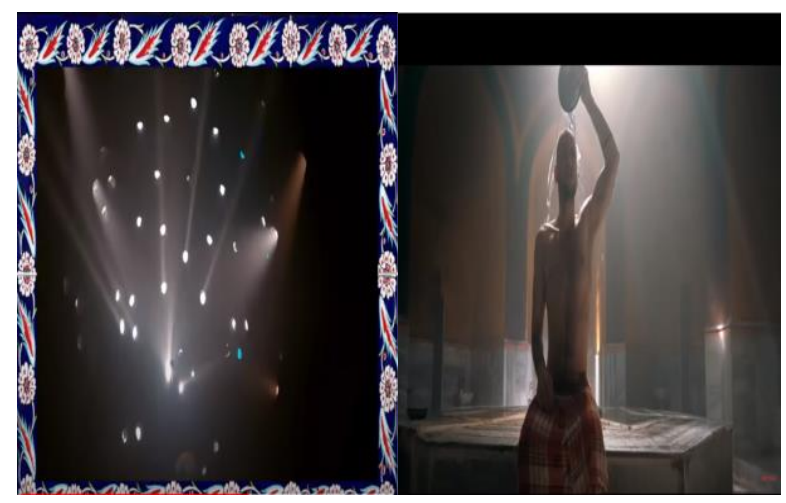

Resim 6. Boyner "Biz̨im Tarұ̣ımı, Güzel” Reklam Filmi Hamam Görseli

Kültürel açıdan bakıldığında; farklı olana karşı yargılar bir bakış açısının sergilendiği görülmektedir. Fakat yeniye karşı sert bir tavır veya korku olmamasından dolayı düşük belirsizlik mesafesinin baskın olduğu söylenebilmektedir. Geleneklere sayg1 gösterilmesi ise kısa dönem oryantasyonuna işaret etmektedir. Kültürel ögeler açısından incelendiğinde ise, Türk hamamı ve hamama ilişkin eşyalar kullanılmaktadır.

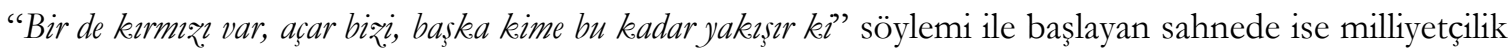
vurgusu fazlası ile yapılmaktadır. Türk bayrağının gösterilmesi yine milliyetçi ifadenin sembollerinden birisi olmaktadır. Aynı sahnede "gol, gol" diye seslenilmesi, Türk kültüründe futbola verilen önemi de ifade etmektedir.

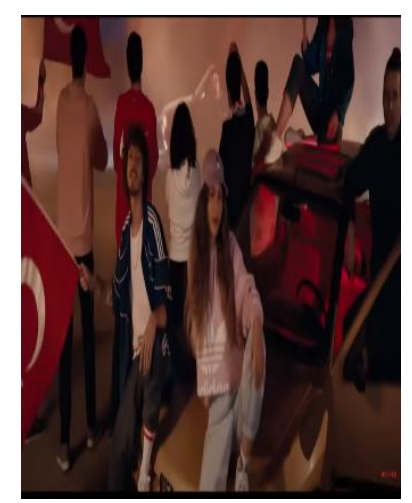

Resim 7.Boyner "Biz̨im Tarẓmız, Güzel”" Reklam Filmi Sokak Görseli

Kültürel açıdan bakıldığında; yurtseverliğin ön plana çıkarılması kollektivzm boyutuna vurgu yapmaktadir.

"Ceket üzerimizde güzel durur gel gelelim belimizde de iyi durur" söylemi ile başlayan sahnede ise Türk kültüründe görülebilecek mahalle dügünü yer almaktadır. Birlik ve beraberlik mesaj1 verilen sahnede samimi arkadaşlık ve dostluk ilişkileri görülmektedir. Kültürel açıdan bakıldığında; kollektivizm boyutu mevcuttur.

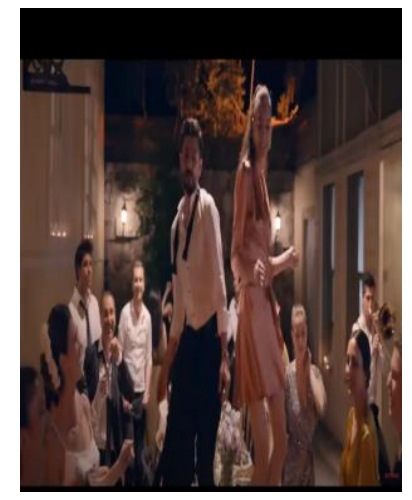

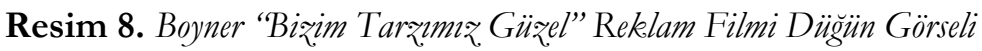


İncelenen reklamın barındırdığı kültürel ögeler ve Hofstede’nin kültür boyutlarına ilişkin incelemesi Tablo 3'de gösterilmiştir.

Tablo 3. Kültürel Ögeler ve Hofstede'nin Kültür Boyutlarna İlişkin Inceleme

\begin{tabular}{|c|c|c|c|}
\hline Kültürün Ögeleri & İçerik & Sahne & $\begin{array}{c}\text { Kültür Boyutlatı bağlaminda } \\
\text { Yorum }\end{array}$ \\
\hline Değerler & $\begin{array}{l}\text { Milli renkler olan kırmızı- beyaza ve } \\
\text { Türk bayrağına yer verilerek milli } \\
\text { değerlere değinilmektedir. }\end{array}$ & $\begin{array}{l}\text { "Bir de kırmızı var, açar } \\
\text { bizi, başka kime bu kadar } \\
\text { yakışır ki” söylemi ile başlar } \\
\text { ve Türk bayrağı görülür. }\end{array}$ & $\begin{array}{l}\text { Reklamda yurtseverlik ön plana } \\
\text { ç1karılmakta ve bu bağlamda } \\
\text { Hofstede'nin kollektivzm boyutu } \\
\text { görülmektedir. }\end{array}$ \\
\hline Dil & $\begin{array}{l}\text { Dilde yabancı kelimeler } \\
\text { kullanılmamakta ve Türkiye'ye yönelik } \\
\text { bilgiler verilmektedir. Türk milletine } \\
\text { dair yardımseverlik, nazardan korkma } \\
\text { gibi özellikler söylemlerle ifade } \\
\text { edilmektedir. }\end{array}$ & $\begin{array}{l}\text { "Kimse inkar edemez bizim } \\
\text { milletçe bir tarzımız var", } \\
\text { "Sadece parklarda sahillerde } \\
\text { koşmayız biz, yardıma } \\
\text { koşmayı da biliriz" ve } \\
\text { "Cesuruz ama nazardan da } \\
\text { korkarız, değmesin diye } \\
\text { neler yapmayız" söylemleri } \\
\text { bulunmaktadır. }\end{array}$ & $\begin{array}{l}\text { Söylemlerde "biz" ifadesinin geçmesi, } \\
\text { reklamı bireycilik boyutundan } \\
\text { uzaklaştırmaktadır. Ayrıca } \\
\text { yardımseverliği göstermesi ve } \\
\text { insanların birbirlerine bağlı olması } \\
\text { hem kollektivizm hem de dişil boyut } \\
\text { vurgu yapmaktadır. Çünkü dişil } \\
\text { boyuta göre muhtaç olanlara yardım } \\
\text { etmek önemlidir. }\end{array}$ \\
\hline İnanış ve Mitler & - & - & - \\
\hline Gelenekler & $\begin{array}{l}\text { Türk toplumunda misafirlere kolonya } \\
\text { dökülmesi, darda kalan insanlara yardım } \\
\text { etmek ve hamama gitmek gibi } \\
\text { geleneksel davranışlar görülmektedir. }\end{array}$ & $\begin{array}{l}\text { Giyim tarzı gelenekselden } \\
\text { uzak olan kızın misafirlere } \\
\text { kolonya döker ve kadınlar } \\
\text { gencin kıyafetini yargıllamaz. } \\
\text { Gençler, yardıma koşar. } \\
\text { Punk tarzında giyinen genç } \\
\text { hamama gider. }\end{array}$ & $\begin{array}{l}\text { Hoşgörülü toplum özelliğini içeren } \\
\text { dişilik boyutu görülmektedir. } \\
\text { Gençlerin geleneklerini yaşadığı } \\
\text { döneme uyarlaması uzun dönem } \\
\text { oryantasyon boyutunu gösterirken, } \\
\text { farklı olanın tehlikeli olarak } \\
\text { algılanmaması ise düşük belirsizlik } \\
\text { mesafesi ile açıklanmaktadır. }\end{array}$ \\
\hline Törenler & $\begin{array}{l}\text { Dügün sahnesi ile Türk kültüründe } \\
\text { görülebilen mahalle dügünleri } \\
\text { resmedilmektedir. }\end{array}$ & $\begin{array}{l}\text { Mahalle arasinda } \\
\text { gerçekleşen düğünde, damat } \\
\text { ve bir kadın masada oynar. }\end{array}$ & $\begin{array}{l}\text { İnsan ilişkilerinin ön plana çıarılması } \\
\text { dişilik ve kollektivizm boyutlarını } \\
\text { açılamaktadır. }\end{array}$ \\
\hline Yasalar & - & - & - \\
\hline $\begin{array}{l}\text { Materyal } \\
\text { göstergeler }\end{array}$ & $\begin{array}{l}\text { Nazar boncuğu, dantel ve çay tabağı } \\
\text { gibi nesneler kullanılarak Türk } \\
\text { toplumunda günlük yaşamda } \\
\text { görülebilecek göstergelere yer } \\
\text { verilmektedir. Ayrıca Türk kültüründe } \\
\text { önemli bir yer tutan çiniler kullanılarak } \\
\text { vurgu yapılmaktadır. }\end{array}$ & $\begin{array}{l}\text { Nazar boncuğu desenli oje } \\
\text { süren kadın, erkeğe } \\
\text { ayakkabısını boyatır. } \\
\text { Genellikle dışarda } \\
\text { kahvehanelerde görülebilen } \\
\text { çay tabağı ve bardaklarda } \\
\text { kadın çay içer. }\end{array}$ & $\begin{array}{l}\text { Erkek ve kadın arasındaki kesin } \\
\text { çizgilerin kalktığını gösteren reklamda } \\
\text { boyut görülmektedir. }\end{array}$ \\
\hline
\end{tabular}

\section{“Hediye Demek, Boyner Demek" Reklam Filminin Analizi}

"Biæ̌i bilen bilir bižim milleţ̦e bir taržmı var" söylemi ile başlayan reklam, "bizim için hediye vermek çok şey demek, mesela bir hediye baktıkça beni hatırlarsın demek, hiç unutur muyum demek, hayırlı olsun demek, helal olsun demek, gönül almak demek, gönül vermek demek, bir yastıkta kocayın demek, kendime alırken sana da aldım demek, içimden geldi demek, bir hediye yeter kalbimizden geçeni söylemeye bizim kalbimiz güzel" söylemleri ile devam etmekte ve bitirilmektedir. Reklamda kullanılan ifadeler incelendiğinde; biz kelimesi kullanılarak birlik vurgusu yapilmakta ve reklamın bencillik boyutundan uzaklaştı̆̆1 görülmektedir. Hediyeleşmenin Türk kültüründeki anlamları Türk halkına özgü ifadelerle anlatılmaktadır. Kültürel açıdan incelendiğinde geleneksel bir olgunun, yabancı kelimelerle anlatılmaması hem geleneksel hem de dil açısından kültürel ögelere yer verildiğini göstermektedir. Hofstede'nin kültürel boyutları açısından incelendiğinde ise söylemde tekil özne kullanılmaması ve insanların birbirlerini hatırlaması gibi ifadelerin kullanılması ile kollektivizmin ön plana çıktığı görülmektedir.

Görsel olarak ise reklam filmi beyaz bir halı üzerinde duran küçük bir hediye kutusu ile başlamaktadır. 


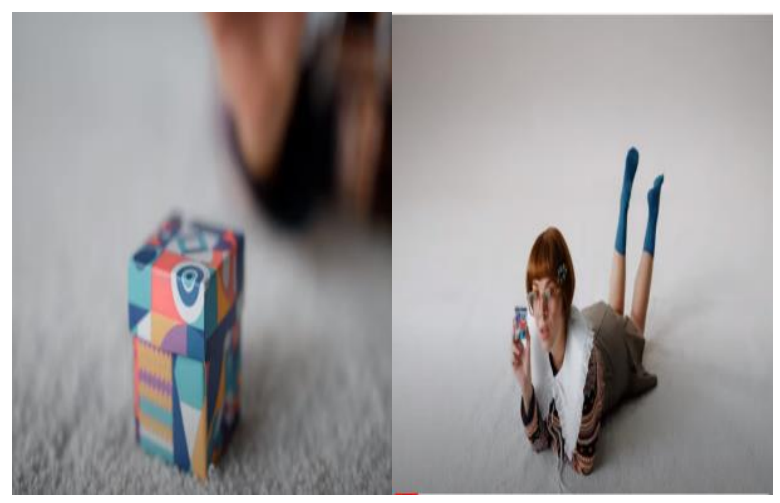

Resim 9. Boyner "Hediye Demek Boyner Demek" Reklam Filmi Açıllş Görseli

İlk sahnede hediye kutusuna vurgu yapılması hediyeleşmenin önemine de vurgu yapılmasının yan sıra heyecan ve merak duygularını uyandırmaktadır. Hediye kutusunun üzerindeki şekiller incelendiğinde ise nazar boncuğu figürü göze çarpmakta ve nazar boncuğu ve kilim deseni gibi geleneksel figürler ile modern olarak nitelendirilen geometrik desenler bir arada kullanılmıştır. Sahnedeki kızın kıyafetleri incelendiğinde ise kıyafetlerin özellikle beyaz yakanın Türk kültüründen ziyade daha çok Avrupa'da görülen kıyafetlere benzediği görülmektedir. Geleneksel kıyafetlerle geçmişi ve piercingler ile de modern dünyayı birlikte yaşatmaktadır. Bakışlar ise kıyafetle verilen çocuksu görüntünün aksine alımlı ve çekicidir. Hediyeler ile şımartılan bir çocuk imajı da çizilmektedir.

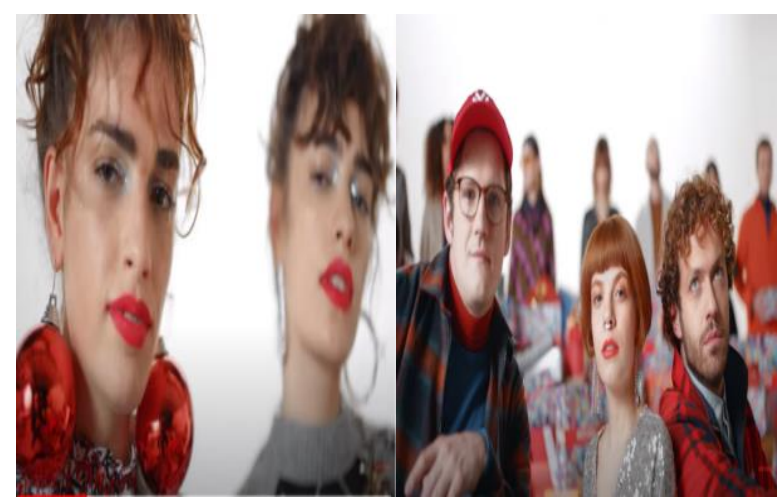

Resim 10. Boyner "Hediye Demek Boyner Demek" Reklam Filmi Görseli

Reklamda karakterlerin piercing takması daha çok Avrupa tarzı olarak değerlendirilmekte ve kırmızı büyük küpeler ise yılbaşı ağaçlarında rastlanılan süsleri anımsatmaktadır. Renkliliğin ve canlılı̆̆ın görüldüğü sahnede yeni bir kimlik ve geçmişten farklı bir yaşam tarzı benimsetilmektedir. Kültürel açıdan değerlendirildiğinde karakterlerin giyim açısından Türk kültüründen ziyade Avrupa tarzına yöneldiği belirlenmiştir. Hofstede'nin kültürel boyutları açısından bakıldığında ise gençlerin özellikle davranış ve giyimleri açısından geçmişlerine bağlı kalmadıkları hatta geçmişi tamamen yok ettikleri görülmekte bu ise uzun dönem oryantasyonu ile açıklanmaktadır.

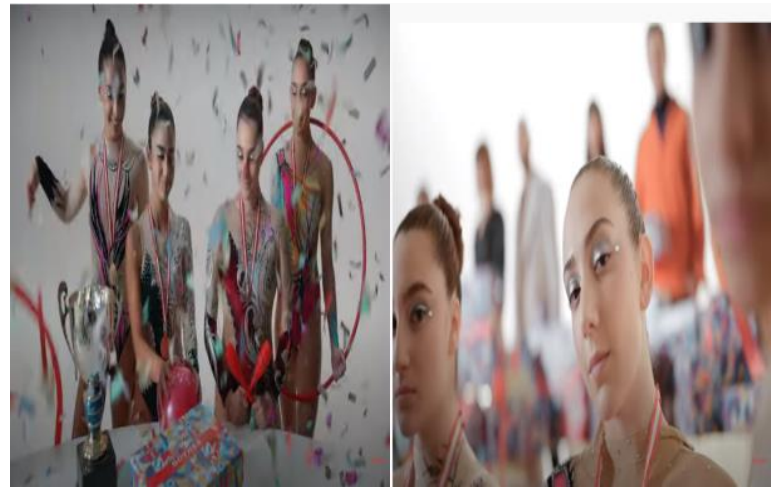

Resim 11. Boyner "Hediye Demek Boyner Demek" Reklam Filmi Kupa Görseli 
Resim 11'de gösterilen kupa sahnesinde ise teknolojinin rengi olan parlak ve gri rengi ve jimnastik yapan kızların bir arada verilmesiyle spor ve teknoloji birlikte yansıtılmaktadır. Özellikle kupa ve hediye kutusunun yan yana durması, ikisinin aynı değere ve öneme sahip olduğuna işaret etmektedir.

"Baktıkģa beni hatırlarsın demek" söylemi ile başlayan sahnede cadılar bayramını hatırlatacak kıyafetleri ile iki kadın görünmektedir. Kadınlar birbirine ayna hediye etmektedir.

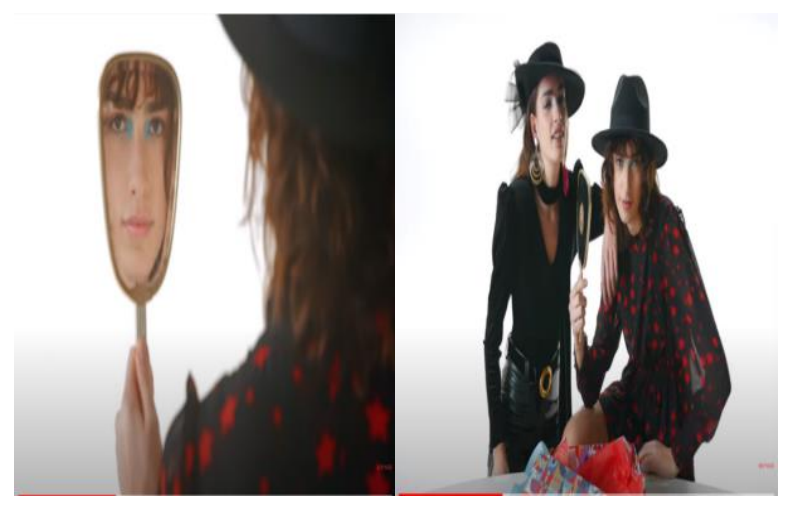

Resim 12. Boyner "Hediye Demek Boyner Demek" Reklam Filmi Ayna Görseli

Bilindiği gibi ayna insana kendisini göstermektedir ve kişiye veya topluma iyi veya kötü tüm özelliklerini yansıtmaktadır ve insanların kendileri ile bağ kurmaları veya insanlarda kendilerini bulmaları yine ayna ile ifade edilmektedir (Sümer, 2017: 1375). Bu bağlamda reklamda kullanılan ayna metaforu ile anlatılan toplumsal gerçekliğin kendisi olmasıdır. Toplumun kültürünün veya yaşam tarzının aynada görünen yüze benzediği anlatılmak istenmektedir. Fakat görünen yüzdeki makyajın marjinal olduğu ve Türk kültürünün geneline bakıldığında Türk kültürünü pek yansitmayan bir profil olduğu görülmektedir. Kültürel açıdan bakıldığında aynanın Türk kültüründe önemli bir yeri olduğu bilinmektedir. Reklamda kullanılan ayna ise Türk toplumunda hamam takımı içerisinde verilen aynalara benzemektedir.

"Bir Yastıkta Kocayın Demek" söylemi ile başlayan sahnede gelin ve damat görülmekte ve yanlarında sadece bir kişi bulunmaktadır.

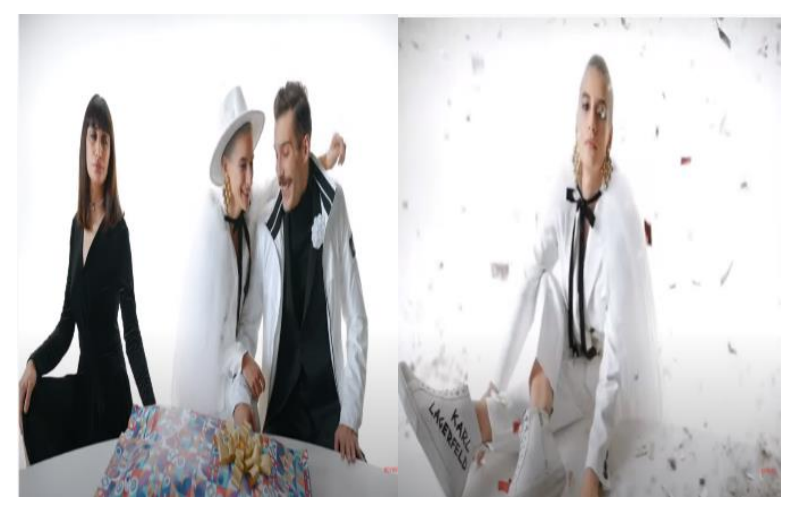

Görsel 13. Boyner "Hediye Demek Boyner Demek," Reklam Filmi Dügün Görseli

Resim 13'de gösterilen gelin ve damat figüründe gelinin geleneksel gelin tarzından farklı olduğu görülmektedir. Özellikle saçları ve tarzı ile geleneksel kadın ve gelin figüründen uzaklaşmaktadır. Gelinin beyaz ayakkabısında siyah yazılı Karl Lagerfeld ismi dikkat çekmektedir. Almanya doğumlu eşcinsel bir moda tasarımcıya ait olan (Hürriyet Kelebek, 2021) bu ismin içerikte maskeli bir anlam içerdiği söylenebilir. Bu kod, farklı cinsel yönelimli bireylerin temsili bakımından değerlendirildiğinde metaforik bir anlama sahiptir. Sosyal kabul yoluyla verilen bu mesaj farklı olana hoşgörülü olma ya da saygı duyma biçiminde yorumlanabilir. Kültürel açıdan bakıldığında geleneksel kalıplardan uzaklaşmış düğün sahnesine yer verilmektedir. Hofstede'nin kültürel boyutu açısından bakıldığında ise yandaki kadının ve diğer insanların bu durumu yargılamaması belirsizlikten kaçınmanın düşük olduğu ile açıklanmaktadır.

Reklamın son sahnesinde ise herkesin Boyner'de birleştiği ve herkesi mutlu edenin ise Boyner yazan hediye kutusunun olduğu anlaşılmaktadır (bkz resim 14). 


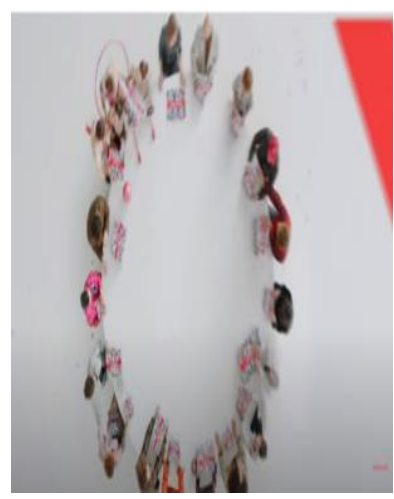

Resim 14. Boyner "Hediye Demek Boyner Demek" Reklam Filmi Kapamıs Görseli

İncelenen reklamın barındırdığı kültürel ögeler ve Hofstede’nin kültür boyutlarına ilişkin incelemesi Tablo 4'de gösterilmiştir.

Tablo 4. Kültürel Ögeler ve Hofstede'nin Kültür Boyutlarnna İliskin İnceleme

\begin{tabular}{|c|c|c|c|}
\hline $\begin{array}{l}\text { Kültürün } \\
\text { Ögeleri }\end{array}$ & İçerik & Sahne & $\begin{array}{c}\text { Kültür Boyutlatı bağlamında } \\
\text { Yorum }\end{array}$ \\
\hline Değerler & $\begin{array}{l}\text { Gönül alma, gönül verme ve } \\
\text { hediyeleşme gibi manevi } \\
\text { değerler }\end{array}$ & $\begin{array}{l}\text { İnsanlar birbirlerine hediye alip } \\
\text { vermektedir. }\end{array}$ & $\begin{array}{l}\text { Arkadaşlık ve hoşgörü duygularını } \\
\text { içermesi açısından sırasıyla } \\
\text { Kollektivizm ve dişil boyut } \\
\text { görülmektedir. }\end{array}$ \\
\hline Dil & $\begin{array}{l}\text { Dilde yabancı kelimeler } \\
\text { kullanılmamakta ve Türkiye'ye } \\
\text { yönelik bilgiler verilmektedir. } \\
\text { Hediyeleşmenin önemi Türk } \\
\text { milletine özgü ifadelerle } \\
\text { anlatılmaktadır. }\end{array}$ & $\begin{array}{l}\text { Bizim için hediye vermek çok şey demek, } \\
\text { mesela bir hediye bakttkça beni hatırlarsın } \\
\text { demek, hiç unutur muyum demek, hayırlı } \\
\text { olsun demek, helal olsun demek, gönül } \\
\text { almak demek, gönül vermek demek, bir } \\
\text { yastıkta kocayın demek, kendime alırken } \\
\text { sana da aldım demek, içimden geldi } \\
\text { demek, bir hediye yeter kalbimizden } \\
\text { geçeni söylemeye bizim kalbimiz güzel }\end{array}$ & $\begin{array}{l}\text { Söylemlerde "biz" ifadesinin geçmesi, } \\
\text { reklamı bireycilik boyutundan } \\
\text { uzaklaştırmaktadır. Ayrıca } \\
\text { hediyeleşmeyi ve insanların } \\
\text { birbirlerine bağlı olması hem } \\
\text { kollektivizm hem de dişil boyut vurgu } \\
\text { yapmaktadır. }\end{array}$ \\
\hline $\begin{array}{l}\text { İnanış ve } \\
\text { Mitler }\end{array}$ & - & - & - \\
\hline Gelenekler & Hediyeleşme & $\begin{array}{l}\text { İnsanlar birbirlerine hediye almakta ve } \\
\text { hediye vermektedir. }\end{array}$ & $\begin{array}{l}\text { Hoşgörülü ve sevgi dolu bir toplum } \\
\text { olarak gösterilmesi dişilik boyutuna } \\
\text { vurgu yapmaktadır. }\end{array}$ \\
\hline Törenler & $\begin{array}{l}\text { Gelin ve damat gösterilerek } \\
\text { düğün sahnesi gösterilmektedir. }\end{array}$ & $\begin{array}{l}\text { Gelin ve damat beyazlar içinde oturur ve } \\
\text { yan tarafta siyahlar içinde biz kız onları } \\
\text { izler. }\end{array}$ & $\begin{array}{l}\text { Gelinin belirgin kadın figürüne sahip } \\
\text { olmaması ve bu tarzın benimsenmesi } \\
\text { düşük belirsizlikten kaçınma boyutu } \\
\text { ile açıklanmaktadır. }\end{array}$ \\
\hline $\begin{array}{l}\text { Materyal } \\
\text { göstergeler }\end{array}$ & Nazar boncuğu & $\begin{array}{l}\text { Reklam filminin ilk sahnesinde hediye } \\
\text { kutusunun üzerinde yer alır. }\end{array}$ & $\begin{array}{l}\text { Kültürel göstergelere önem verildiğini } \\
\text { ifade etmekte ve kısa dönem } \\
\text { oryantasyonun bulunduğu } \\
\text { söylenebilir. Kısa dönem } \\
\text { oryantasyonunda geleneklere bağllllk } \\
\text { önemlidir. }\end{array}$ \\
\hline
\end{tabular}

\section{Tartışma, Sonuç ve Öneriler}

Reklamların, toplumların düşünce yapılarında ve davranış şekillerinde etkili olduğu bilinen bir gerçektir. Reklamların, toplumların bakış açısına yön vermede ve toplumsal değerlerin oluşmasında ve yönlendirilmesinde etkili (Mengü, 2005, s. 115) olmasından dolayı Boyner reklamları kültürel temsil bakımından anlamlı veriler içermektedir. Çalışmaya genel perspektiften bakıldığında her iki reklamda kurulan kültürel söylemler Türklerin yaşam biçimlerine ait temsiller içermektedir. Bu temsiller reklamların kültürel bir gösterge olduğunu destekler niteliktedir. Diğer taraftan analize dâhil edilen reklamlarda karakterlerin yaşadıkları koşullara geleneklerini uyarladıkları fakat giyim, eğlence ve yaşam tarzları noktasında Türk kültüründen uzaklaşmaya başladıkları görülmektedir. Toplumdan topluma değissen kültürel ögelerin, reklamlarda işlenme sorunsalına vurgu biçiminde tanımlanabilecek bu bulgu dolayısıyla 
anlamlıdır. Çünkü reklam ve kültür etkileşimi içerisinde tüm ülkelere ait norm ve değerlerin kodlanma biçimi reklamlarda oluşturulan kültürel göstergelerle tanımlanmaktadır.

Kültürel boyutlarının ve kültürel ögelerinin içerik ve söylem analizleri kullanılarak incelendiği ilk reklamda; Türk gelenek göreneklerine ait birçok simgenin kodlandığ1 görülmektedir. Türk Bayrağ1 renklerinin (kırmızı ve beyaz) kullanılması, bayrak, nazar boncuğu, hamam, dantel, çay ve düğün gibi kültürel ögeler bu bağlamda Türk kültürüne ait belli temsil alanlarıdır. Anlatı yapısı içerisindeki geçmiş ve bugüne ait kültürel ögeler, geçmiş ve gelecek arasında bir köprü oluşturma durumu olarak yorumlanabilir. Bu bağlamda marka, geçmiş ve geleceği birleştiren, sınıflar arası veya kuşaklar arası çatışmayı bitiren, bu tarz sorunları çözen imaj çizmektedir.

Kültür vurgusu, görsellerin yanı sıra söylemlerle de yapılmaktadır. Reklam içerisinde kullanılan metinlerde, birlik mesajlarına yer verilmektedir. "Biz" kelimesinin sıkça kullanılması ve Türk milletine özgü ögelere temel vurgu yapan özelliklerinin yinelenmesi milliyetçilik ögesiyle açıklanabilir. Reklamda karakterler, genel olarak geçmişle geleceği bir arada yaşayan bireyler olarak anlatılmaktadır. Geçmişten destek alan her bir karakter geleceğine yön verebilmektedir. Fakat gençlerin tavır ve giyim tarzlarının Türk kültüründen uzaklaştı̆̆ da bir gerçektir. Karakterlerin misafirlere kolonya dökme, yardımlaşma, hamama gitmek gibi gelenekleri devam ettirmelerine rağmen giyim ve yaşam tarzı açısından Avrupai tarzı daha fazla benimsendikleri ve Türk kültüründen uzaklaştıkları düşünülmektedir. Reklamda gençlerin giyimlerinin geleneklerle uyuşmadığı ise reklamda yer alan "bazen dışarıdan bakan der ki bu da bir değişik" söylemi ile desteklenmektedir.

Hofstede'nin kültür boyutları bağlamında değerlendirildiğinde de gerek söylemlerle gerekse de görüntülerle birlik ve beraberlik vurgusu yapılmaktadır. Bencillik veya bireysellik mesajlarına yer verilmemiştir. Bu durum ise toplulukçuluk yani kollektivizm vurgusunun yoğun bir şekilde yapıldığını göstermektedir. Kültürden uzaklaşmalarına rağmen gençlerin kıyafetlerinin veya davranışlarının yadırganmadığı ve kabullenildiği anlaşılmaktadır. Bu bağlamda ise düşük belirsizlikten kaçınma boyutunun yer aldığı söylenebilmektedir. Aynı şekilde gençlerin geleneklerine bağlı kalmamaları, yeni bir yaşam tarzı benimsemeleri ve geleceğe dönük olmaları ve geleneklerini yaşadıkları zamana uyarlamaları uzun dönem oryantasyon boyutu ile açıklanmaktadır. Gençlerin yardıma muhtaç kişilere yardıma koşmaları ve insanların birbirlerine hoşgörülü davranmaları ise dişilik boyutunu göstermektedir.

İncelenen ikinci reklamda ise sadece Türk kültüründe önemli yeri olan hediyeleşme olgusunun üzerinde durulmuş ve bu durum kültürel dil kullanılarak anlatılmıştır. Reklamda kullanılan söylem incelendiğinde hediyeleşmenin anlamları kültürle özdeşleşen şekilde açık ve net anlatılmaktadır. Reklamda karakterlerin giyimleri açısından geleneksel tarzdan uzaklaşıp Avrupa tarzına yöneldikleri ve hatta geçmişleri ile aralarında bir bağ kalmadığı anlaşılmaktadır. Bu ise onları Türk kültüründen uzak bir yere konumlandırmıştır. İncelenen reklamda kültürel öge olarak nazar boncuğu ve aynanın kullanıldığ1 görülmektedir. Türk kültüründe mevcut olan aynada yansiyan yüzün ve evlilik sahnesindeki gelinin tarzı ise Türk kültüründen farklı olduğu görülmektedir. Reklamda kullanılan ayna metaforu değerlendirildiğinde; aynadaki yüzün toplumu yansıttı̆̆ı düşünülmektedir. Fakat aynadaki yüzün daha çok Avrupa tarzında bir makyaj olduğu görülmektedir. Evlilik sahnesinde ise gelinin geleneksel ve kültürel olarak bilinen gelin imajının yerine farklı bir gelin imajının olduğu görülmektedir.

Hofstede'nin kültürel boyutlanı açısından bakıldığında ise gençlerin hediyeleşme haricinde kültürel bağlılıklarının kalmadığı ve tamamen geleceğe yöneldikleri ve içerisinde bulundukları çağa uyum sağladıkları görülmektedir. Bu durum ise uzun dönem oryantasyonuna değinildiğini göstermektedir. Özellikle hediyeleşmenin anlatıldığı reklamda bireysellikten uzak bir mesaj verilerek kollektivizm boyutuna vurgu yapılmaktadır. Arkadaşlığı ve hoşgörülü bir ortamın gösterilmesi ile dişilik boyutuna değinilmektedir.

\section{Etik Beyan}

"Kültür ve Reklam İlişkisi" başlıklı çalısmanın yazım sürecinde bilimsel kurallara, etik ve alıntı kurallarına uyulmuş; toplanan veriler üzerinde herhangi bir tahrifat yapılmamış ve bu çalışma herhangi başka bir akademik yayın ortamına değerlendirme için gönderilmemiştir. Bu araştırma doküman incelemesi olarak yapıldığından etik kurul kararı zorunluluğu bulunmamaktadır. Fakat Boyner Grup Kurumsal İletişim Koordinatörü ile iletişime geçilerek kendilerinden izin alınmıştır. 


\section{Kaynakça}

Abdelaal, N. M. ve Sase, A. S. (2014). Advertisement analysis: A comparative critical study. Advances in Language and Literary Studies, 254-259.

Aktuğlu, I. K. ve Çolakoğlu, B. E. (2011). Kültürün reklam üzerindeki etkisi: Reklam biçimlerinin kültür tarafindan belirlenmesi. Yeni Düsünceler, 9-23.

American Marketing Association. (2020, Aralı). American Marketing Association: https://www.ama.org/topics/advertising/ adresinden alınd1

Arslan, E. (2014). Türkiye'de reklam sloganlarının gündelik dil pratikleri üzerindeki etkisinin değerlendirilmesi: Ege üniversitesi öğrencilerine yönelik bir araştırma. Marmara İletişim Dergisi, 57-72.

Balc1, A. (2016). Sosyal bilimlerde arastırma yöntem, teknik ve ilkeler. Ankara: Pegem Akademi Yayıncilık.

Çetin, B. N. (2014). Yeniden anlamlandırma aracı olarak reklam. International Periodical For The Languages, Literature and History of Turkish or Turkic, 559-573.

Elden, M., Ulukök, Ö. ve Yeygel, S. (2005). Şimdi reklamlar (7.Baskı). İstanbul: İletişim Yayınları.

Ghandeharion, A., ve Badrlou, L. (2018). Iranian advertisements: A postcolonial semiotic reading. Kasetsart Journal of Social Sciences, 334-342.

Görgün, M. R. (2020). Uluslararası pazarlara giriş stratejileri. M. R. Görgün içinde, Uluslararası pazarlama (s. 1-171). Ankara: Akademisyen Kitapevi.

Hartnett, N., Romaniuk, J. ve Kennedy, R. (2016). Comparing direct and indirect branding in advertising. Australasian Marketing Journal (AMJ), 20-28.

Hürriyet Kelebek. (2021, Şubat 10). Hürriyet Kelebek: https://www.hurriyet.com.tr/kelebek/escinsel-oldugumuanneme-soyleyince-17681672 adresinden alınd1

Karadeniz, M. (2020). Postmodernizm ve Türk öykücülüğündeki yansımaları. Biə̨im Külliye, 51-54.

Koç, E. (2019). Tüketici davranısı ve pazarlama stratejileri global ve yerel yaklaşım. Ankara: Seçkin yayıncilık.

Kotler, P. (2018). A'dan Z'ye paz̧arlama (Çev. A. K. Bakkal). İstanbul: Mediacat.

Mengü, S.Ç.(2005). Reklamın toplumsal değer yapılanmasına etkisi. İstanbul Üniversitesi İletişim Fakültesi Dergisi, 3(3), 113-132.

Mucuk, İ. (2014). Pazarlama ilkeleri (20.Bask1). İstanbul: Türkmen Kitapevi.

Odabaşı, Y., ve Barış, G. (2017). Tüketici davranışı (17.Baskı). İstanbul: Mediacat.

Okumuş, A. (2018). Tüketici davranışı. İstanbul: Türkmen kitapevi.

Özcan, B. A. (2018). Türk ve Slav kültüründe siyah renk. Akademik Tarih ve Düsünce Tarihi, 269-292.

Peltekoğlu, F. B. (2010). Kavram ve kuramlaryla reklam. İstanbul: Beta Basım Yayım Dağıtım.

Saylık, A. (2019). Hofstede'nin kültür boyutları ölçeğinin Türkçe'ye uyarlanması; geçerlik ve güvenirlik çalışması. Uluslararası Türkeçe Edebiyat Kültür Ë̈itim (TEKE) Dergisi, 1860-1861.

Srivastava, R. K. (2010). Effectiveness of global advertisement on culture of India:an emerging market. International Journal of Emerging Markets, 102-113.

Stemler, S. (2000). An overview of content analysis. Practical Assessment, Research, and Evaluation, 1-6.

Sucu, İ. (2020). Reklam uygulamalarında kültürlerarası iletişimin ve kıyafet kullanımlarının etkisi. Insan ve Sosyal Bilimler Dergisi, 392-404.

Topsümer, F. ve Elden, M. (2016). Reklamcllk kavramlar, kararlar, kurumlar (15.Baskı). İstanbul: İletişim Yayınları.

Türk Dil Kurumu Sözlükleri. (2020, Aralık). Türk Dil Kurumu Sözlükleri: https://sozluk.gov.tr/ adresinden alınd1

Uribe, R. (2016). Separate and joint effects of advertising and placement. Journal of Business Research, 459-465.

Weber, R. P. (1990). Basic content analysis. New Delhi: Sage Publications.

Yeşil, S. (2012). Türkiye'nin ulusal kültürel özellikleri ve yenilikçilik potansiyeli arasındaki ilişki açısından bir değerlendirme. Mustafa Kemal Üniversitesi Sosyal Bilimler Enstitüsü Dergisi, 33-62.

Yılmaz, M. ve Mazlum, H. (2009). Kültürel motiflerin reklam üzerinde kullanımı: Türk Hava Yolları lale motifi örneği. Akdeniz Sanat Dergisi, 59-69.

\section{EXTENDED ABSTRACT}

Advertisements aiming to inform, remind and persuade are one of the promotion tools. Advertisements become important for businesses that want to increase their national and international marketshare. It is especially important for businesses that want to enter international markets to know the cultural characteristics of societies. Culture is the set of symbols or elements shared by society, such as values, traditions, beliefs, and moral rules that affect the purchasing behavior of consumers. The fact that although mice are considered ad God in India, people have negative feeling about them in Turkey explains cultures can vary from community to community. Also, the fact that pork that prefers in European countries is banned in İslamic countries can be given as an example of the values or beliefs shared by the society.

Five cultural dimensions were determined by Hofstede to examine the cultures of societies. These are Power Distance, Individualism- Collectivism, Masculinity- Femininity, Uncertainty Avoidance and Long- 
Term Orientation- Short-term orientation. Especially, the relationship between advertising and culture makes cultural dimensions important. The relationship between advertising and culture can be seen in two ways. Advertisements reflect the values and beliefs of people, considering the cultures of the societies and can ensure that products or services are adopted by the society. For example, producing special advertising content for the days which are important for the society or writing the names that are widely used in that country on the labels of the products show that the ads are affected by the culture. On the other hand, advertisements can affect the culture of the society because they have the power to change people's thoughts, behaviors and habits. For example, the fact that a discourse used in advertisements is used in daily speaking language or the roles of men and women are determined through the content in the ads can explain that the ads affect the culture. In this study, which aims to reveal how culture is handled in advertisements, cultural elements which are in advertisements will be analyzed within the scope of Hofstede's cultural dimensions. In this context, Boyner advertisements with the slogan "Bizim Tarzimız Güzel" and "Hediye Demek Boyner Demek" were analyzed with content and discourse analysis. The following questions were determined within the framework of the subject that the study examined:

- What cultural elements of the society are included in the advertisement?

- How are cultural elements positioned in the advertisement?

- Which discourses have been highlighted as a cultural emphasis?

- How are characters used in the advertisement to represent culture?

- Which cultural dimensions of Hofstede have been mentioned?

- What did ads role play in terms of the relationship between advertising and culture?

In the first advertisement examined, it is seen that the use of red and white colors, which are the colors of the Turkish Flag, and cultural elements such as flags, evil eye beads, baths, lace, tea and weddings. Cultural elements used in the advertisement can give information about on building a bridge between the past and the future. In this context, the brand creates an image that unites the past and the future, ends the conflict between classes or generations, and solves such problems. Union messages are given in the discourses used in the advertisement. The emphasis on culture is made with discourses as well as images. In the advertisement, characters are generally described as individuals living with the past and the future. Although the characters continue the traditions such as helping each other and going to the bath, it is thought that they adopt the European style more in terms of clothing and lifestyle and move away from Turkish culture. Unity messages are included in the texts used in the advertisement. It is seen that collectivism which is one of the Hofstede's cultural dimension is emphasized on the ads. However, the main theme of the advertisement is low avoiding uncertainty and long term orientation dimensions. Although the clothes of young people do not fit Turkish culture, they are not excluded by society. Young people adapt their traditions according to the period in which they live.

In the second advertisement examined, only gift which has an important place in Turkish culture was emphasized. This is described using cultural language. In the advertisement, the characters moved away from the traditional style and turned towards the European style. In terms of Hofstede's cultural dimensions, the long-term orientation dimension is mostly mentioned.

In general, with the discourses used in both advertisements, the elements of Turkish culture are expressed accurately and completely by using cultural language. Cultural materials and cultural elements were successfully mentioned. 